\title{
$\backsim$ Formación de posgrado en arquitectura y patrimonio en España
}

\section{Trabajo patrimonial y formación de los profesionales. Apuntes en el tiempo}

Eduardo Mosquera Adell

La posesión de un título universitario puede vincularse entre otras cosas al ejercicio de una determinada profesión en sus diversas modalidades o, pongamos por caso, otorga capacidad para optar a ciertas escalas funcionariales. A partir del acceso a la titulación no se manifiesta necesariamente otra exigencia formativa reglada dentro del estatus alcanzado, aunque a lo largo de la biografía de un profesional muchos de los aspectos que lo modelaron como tal pueden resultar seriamente cuestionados u olvidados. A lo sumo, el sentido común dictaría que cada titulado deberá adecuarse a la evolución de los marcos normativos o legislativos y a un "estar al día" en métodos, técnicas... que su profesionalidad estimulará, normalmente de manera bien diversa a la carta del plan de estudios universitarios que haya seguido.

Aunque desde Alberti ya se había reflexionado y practicado de una u otra forma sobre la cuestión, no es sino iniciado el siglo XIX (Stern, Valadier...) cuando, de un modo más decidido, se fue incorporando el conocimiento arquitectónico y por tanto la cultura del proyecto arquitectónico, al trabajo tutelar sobre el patrimonio inmueble cuya responsabilidad última iban asumiendo poderes públicos y asociaciones. Y aunque la planificación urbana -otro territorio que frecuenta el arquitecto- también tomará progresivamente una parte activa en dicha labor patrimonial, donde fundamentalmente este profesional se erige en cualificado protagonista sobre los destinos de la realidad física de tan importante parcela como es el legado cultural, será bajo la actividad restauradora, capaz de centrar de una forma más decidida las posiciones y protagonizar la acción de los profesionales de la arquitectura en dicha esfera.

En nuestro país esta misión, sin embargo, no se verá recogida en los sucesivos planes de estudio que, en periodos convulsos para el perfil del arquitecto, marcados por sustanciales cambios de la arquitectura como respuesta a la modernidad, relegarán la formación del arquitecto en materia patrimonial casi a la nula expresión. Se pretenderá salvar en el mejor de los casos con la impartición de aspectos puntuales en asignaturas con objetivos docentes muy diversos y con el efímero discurrir de una especialidad de Restauración, superada por las convencionales de Urbanismo y Edificación.
Es bien sabido que la labor restauradora española se convirtió en una actividad marginal y de especialista, gracias a la escasez de intervenciones y a su presumible dificultad para el arquitecto común, más interesado en otros menesteres que lo perfilaban además como moderno creador y lo involucraban con un mercado que crecerá galopantemente. La estructura de los arquitectos de Zona -"los siete magníficos"-, a lo sumo complementada con colaboradores y arquitectos diocesanos, presidirá durante décadas el desenvolvimiento de nuestra cultura restauradora, hasta alcanzar prácticamente a nuestra transición democrática.

La relación del maestro con el discípulo o colaborador será clave para la transmisión de unos saberes en los que escasea la literatura arquitectónica y que casi siempre son difícilmente contrastables sino es en la directa materialidad de sus trabajos de restauración. En España, las intervenciones sobre el Patrimonio Histórico que han configurado una doctrina con personalidad propia son pocas y aún permanecen insuficientemente estudiadas. Su relevancia apenas rebasa nuestras fronteras.

Generaciones posteriores a los arquitectos de Zona alimentaron su sed de conocimiento, generalmente empujados por los maestros, acudiendo a cursos fuera de España. Italia, más concretamente Roma, sería el lugar más apropiado para alcanzar certidumbres y aggiornamento preciso. El ICCROM se convertía en referente para una minoría que enlazaba con naturalidad el refugio académico de la restauración española con la adecuación a técnicas más avanzadas y criterios más evolucionados.

Pero los años ochenta vieron incrementarse el número de intervenciones y de arquitectos actuantes. Los parámetros para elegirlos debieron basarse en la calidad genérica del profesional, que aportaría una visión de modernidad frente a una falta de experiencia y formación en el terreno patrimonial. Los encargos alcanzarían una escala gradual de dimensión y complejidad, discurriendo algunos arquitectos paulatinamente por la senda del "aprender haciendo", en razón a la formación convencional y deficitaria que sufrían en nuestras escuelas. Las intervenciones, explicadas en jornadas que sirvieron de balance profesional (como las ministeriales de 1987) y difundidas en numerosas y significativas publicaciones, en medio de vivas polémicas alcanzaron resultados muy variables, en los que se vio involucrado todo el Gotha de la arquitectura española junto a profesionales de muy desigual aptitud y reconocimiento.

El problema de raíz es que la evolución de los profesionales en general y concretamente de los arqui- 
tectos, una vez obtenido su título, no ha sido desde luego una preocupación tradicional de la universidad. A pesar del perfil generalista del título de arquitecto, a lo sumo esta institución de origen medieval se ha esforzado en configurar el doctorado, que en gran medida cualifica a los propios efectivos de los que se nutre. $Y$ el doctorado para los arquitectos, además, evolucionó de un perfil netamente profesional (se alcanzaba el grado de doctor presentando un proyecto, un trabajo profesional) para asumir finalmente, como en otras titulaciones, la labor investigadora en sentido estricto, obligando al doctorando a realizar una tesis doctoral. Esta situación fue lo suficientemente tardía para que las primeras tesis se defendieran prácticamente a finales de los sesenta o al abrirse los años setenta.

La falta de estructuración de los estudios y la investigación arquitectónica universitaria respecto a las acciones básicas de la tutela patrimonial, con pequeñas dosis sobre restauración y algo de protección, conduciría al aporte de experiencias individuales no regladas como vía de formación. La escasez de investigación arquitectónica con una perspectiva patrimonial terminaría por subrayar la confirmación de la universidad como una institución que mantenía un bajo pulso en relación al patrimonio, justo en el momento en que socialmente (años setenta y ochenta) fue objeto de creciente reivindicación y adecuación a los parámetros de las sociedades culturalmente más avanzadas.

La solución a la indiferencia de la institución universitaria se fue paliando de diversas maneras. En ocasiones, la preocupación de algunos profesores universitarios ha motivado la definición puntual de actividades de extensión dedicadas a la formación en materia restauradora (seminarios, aulas...), donde han volcado con responsabilidad su saber y experiencia; en otras, han sido las pasarelas de las universidades estivales o los colegios profesionales -con el célebre curset barcelonés como paradigma-, quienes siguiendo los cambiantes rumbos sobre restauración y más bien centrándose en cuestiones como la rehabilitación o la problemática de los llamados centros históricos, han pergeñado diversas fórmulas que permitieron actualizar -e incluso formular- la preparación de los profesionales de la arquitectura en cuestiones patrimoniales. Bastaría recordar la labor de Fernando Mendoza, Francisco Pol y tantos otros en este sentido. En estas actividades se harán habituales los nombres de arquitectos especialistas como Enrique Nuere, Ignacio Gárate, Juan López Jaén, Antonio Almagro o Pablo Latorre... además de responsables de diversas instituciones como Dionisio Hernández Gil, Alberto Humanes, Leopoldo Uría, Carlos Baztán, Antoni González, Román Fernández-Baca, Julián Esteban... junto a universitarios como Ignasi de Solà-Morales, Antonio Fernández Alba, Antón Capitel, Juan Miguel Hernández de León, Antonio Mas-Guindal, etc. y que en Andalucía protagonizan profesores como Alfonso Jiménez, Víctor Pérez Escolano, Javier Gallego... además de bue- na parte de los profesionales más activos, encargados todos ellos de dar un plural cuerpo al papel de la arquitectura española en el Patrimonio desde la historia, la teoría, el proyecto y la intervención, o la gestión, por no alargar la nómina incluyendo a historiadores, arqueólogos y otros perfiles.

Las múltiples expresiones de los protagonistas de esa situación y su presencia en el marco institucional, dominando la actividad arquitectónica volcada al Patrimonio, debían culminar en una actividad formadora, que finalmente compartirán con una generación de universitarios formados con ellos que afrontará el compromiso de construir un nuevo espacio docente.

Parecía llegada la hora de articular nuevos marcos formativos y la vía más factible eran los postgrados. En ese momento, el desarrollo de ese tipo de formación tiene como referencia original a determinadas experiencias anglosajonas que luego se internacionalizarán, imitando incluso sus denominaciones. No debemos extrañarnos de que instituciones ajenas a la universidad pública como fundaciones o empresas privadas produjeran en España los primeros desarrollos de postgrados, compitiendo con los reclamos foráneos y auspiciando una impronta elitista.

No será pues hasta la década de los noventa cuando desde la universidad se entienda inexorablemente que este tipo de formación es una demanda real, en expansión, a la que hay que responder cumplidamente. Entonces se valorará además el hecho de que puede convertirse en un vínculo más ágil y flexible con la sociedad que la rígida escena de los dos ciclos, en la casi siempre masificada "fábrica de títulos", o el académico doctorado, teóricamente vinculado a la investigación. Irrenunciablemente, la evolución del mundo profesional debía recogerse y alimentarse.

Las enseñanzas propias se convertirán en una parcela de una importancia creciente en el conjunto de actividades de la institución universitaria -basta observar su multiplicación- al tiempo que surge la perspectiva de la formación continua, con una planteamiento curricular más evolucionado.

Cuando aún los planes de estudio para el título de arquitecto no abordan una respuesta sólida y realmente decidida, los postgrados tienden a remediar algunos de los males de la universidad pública: resolver carencias e inercias propias en el dominio de lo patrimonial, salvar la fragmentación departamental para desarrollar el trabajo interdisciplinar, establecimiento de puentes universidad-sociedad más efectivos, etc. La irrupción de postgrados -generamente con el formato de master- destinados a los arquitectos y otros profesionales relacionados con el trabajo patrimonial será una consecuencia lógica y convergente de los diferentes procesos que someramente hemos enunciado.

El resultado es la aparición y consolidación de una serie de estudios de postgrado con formato de mas- 
ter universitario, más un sinnúmero de cursos de expertos o especialistas. Salpicando nuestra geografía, se corresponden mayoritariamente con la existencia de Escuelas de Arquitectura (alguna como la de Madrid incluso tiene dos). El sello politécnico de origen de estos centros no se puede olvidar, aunque en casos como Sevilla, el propio carácter generalista de su universidad alimentará otra concepción.

Además de la madrileña Fundación Camuñas y su experiencia en la materia con un master de iniciativa privada, debemos recordar que cuentan con docencia de master las siguientes ciudades:

Conservación y Restauración: Madrid

Restauración: Valladolid, Barcelona, A Coruña y Madrid

Rehabilitación patrimonio edificado: La Laguna

Restauración y Rehabilitación: Alcalá de Henares

Patrimonio arquitectónico: Donostia/San Sebastián

Arquitectura y Patrimonio Histórico: Sevilla

Conservación, restauración y rehabilitación son recurrentes en la denominación mayoritaria, aludiendo al patrimonio edificado, monumentos de arquitectura, patrimonio arquitectónico y urbano. Se aprecia una paulatina aunque parcial aproximación a la terminología que una sociedad democrática se ha dado a sí misma con su marco legislativo para lo patrimonial. Su extremo será la opción de configurar una élite más amplia, pero élite al fin, identificada por formarse en la "alta tecnología" de la restauración como parcela de gran exigencia en el seno del trabajo patrimonial.

La insistencia en estos términos puede hacernos entender que basta con suplir carencias en la formación reglada del arquitecto para que trabaje mejor en un terreno "que le es más propio", y que hay que defender y poner al día, y al que antes se accedía por vericuetos muy estrechos y minoritarios. Podríamos hablar de una mejoría (conceptual, técnica...) desde una continuidad, cuando no resistencia, que prefiere seguir operando desde una visión simplemente actualizada de un saber tradicional, de base netamente disciplinar, que estos cursos de postgrado reiteran y amplifican.

Estas posiciones, sin embargo, no pueden obviar la mayor apertura a estos conocimientos que un creciente número de futuros arquitectos ya reciben. Por ejemplo, mediante los programas europeos de movilidad del alumnado, que les permiten formarse en los rudimentos básicos de la restauración (historia, teorías, técnicas...) que imparten facultades con una sólida tradición académica como las italianas de Arquitectu$\mathrm{ra}$, con materias que se repiten insistentemente en la oferta de algunos postgrados españoles. Sin olvidar que algunas escuelas españolas -como las andaluzas, aunque cada una con planteamientos bien diferentes- han comenzado, al fin, a abordar la preocupación por lo patrimonial intentando proporcionar formación cuando menos básica sobre Arquitectura y Patrimonio, eso sí desde el interior de la disciplina.
Sin embargo, caben otros planteamientos en las enseñanzas propias implicadas con el Patrimonio Histórico. Desde compromisos plenos a parciales, existe otra opción -caso del master sevillano y de determinados segmentos en otros- que emerge de forma diferente a la del clásico master en restauración. Según la cual un master debe servir para algo que no hace la titulación de licenciado, arquitecto o ingeniero en la órbita patrimonial: para situar al profesional en un marco más amplio y consecuente, desde el que, en primer lugar, estructurar su capacidad operativa como profesional y, en segundo, organizar su formación en continuidad, racionalizándola frente a toda una selva de ofertas que permanentemente se le presentarán: postgrados, cursos de extensión, universidades de verano... y demás puestas al día. De ahí el interés de un master menos finalista, más basado en criterios de generalidad y de apertura. Esta posición sólo puede formularse como proyecto docente desde el reconocimiento de que los bienes culturales ya se encuentran en otro escenario y que se requieren otras formas de trabajo patrimonial. Haría falta entonces una enseñanza que respondiera, de entrada con un carácter experimental, a esa actitud generalista de asumir la globalidad de la tutela, y articulada en último caso con cursos de especialización y otras actividades de formación propias de instituciones en las que reside la especialización más avanzada (determinados Institutos de Patrimonio, principalmente). La formación adquirida en el master dotaría de una matriz o rejilla sobre la que se incorporarían actualizaciones, desde la experiencia profesional e institucional a la evolución de la formación continuada. Esta estructura no la puede proporcionar la universidad en exclusiva y se hace necesario el concurso de otros protagonistas.

Si unos cursos son en general fruto de una dinámica universitaria meramente endógena en la primera opción, restauracionista, en esta segunda vía un master tiene en cambio que crearse configurando espacios de encuentro con la administración. Que debe ser la principal preocupada y afectada, la estimuladora de las iniciativas probablemente más avanzadas en este territorio de la formación patrimonial. El complemento será la incorporación articulada de diferentes agentes en la labor formadora (profesionales experimentados, otras instituciones, tejido empresarial...).

La idea de generalidad en lo patrimonial es inherente a la integralidad de la tutela. Meter a la arquitectura en situación respecto al ordinario o evolucionado desenvolverse del trabajo patrimonial será algo más que suplir carencias. Se deberá propiciar un obligado encuentro entre disciplinas (algunas identificadas con las titulaciones universitarias existentes, incluyendo las de "última generación"), ante la complejidad de conocer y de hacer. $Y$ también ante la multiplicidad de acciones para las que hay que estar preparado y que son características del trabajo patrimonial. Un master será forzosamente un escenario hacia lo transdisciplinar y por ende requiere de un instrumento específico para su manifestación transdisciplinar: el proyecto patrimonial. 
A estas alturas no podemos aislarnos en la confortable especialización y en el predominio de una sola acción (conservar, restaurar...). Muchas otras disciplinas han salido al encuentro de la arquitectura para compartir el trabajo patrimonial y localizan su espacio en estos postgrados. Un alumnado cada vez más heterogéneo (por procedencia y necesidades) se interesa por estas cuestiones. Por ello, los proyectos docentes deberán ser crecientemente flexibles y adaptables obligándose a incluir un indiscutible perfil investigador. Un master debe ser un laboratorio y también un cauce para un torrente de ideas.
Y la consecuencia no sólo será un desafío permanente en la vertiente investigadora y docente de la universidad. También, y esto es aún más importante, en la del trabajo patrimonial, que tutela la administración desde sus diversas instancias y se implementa con actores cada vez más diversos. En definitiva, la amplia oferta formadora existente tendrá su razón de ser en cuanto sea capaz de medirse con la realidad de las exigencias patrimoniales y sea capaz de desbordarla con la operatividad de sus propios resultados.

\section{Oferta de formación de posgrado en arquitectura y patrimonio en España}

\author{
ANDALUCÍA \\ - Máster en Arquitectura y Patrimonio Histórico \\ CANARIAS \\ - Máster Internacional en Rehabilitación del Patrimo- \\ nio Edificado

\section{CASTILLA LEÓN} \\ - Máster Universitario en Restauración Arquitectónica \\ - Especialista Universitario en Ciencias Auxiliares \\ para la Restauración del Patrimonio Histórico \\ - Especialista Universitario en Técnicas y Procedi- \\ mientos para la Restauración del Patrimonio His- \\ tórico \\ - Especialista Universitario en Teoría y Análisis del \\ Patrimonio Histórico

\section{CATALUÑA} \\ - El Proyecto: Aproximaciones a la Arquitectura des- \\ de el Medio Ambiente Histórico y Social (Máster) \\ - Historia, Arte, Arquitectura y Ciudad (Máster) \\ - Restauración de Monumentos de Arquitectura \\ (Máster) \\ - Arquitectura y Artesanía (Posgrado) \\ - Formas de Análisis e Intervención en el Patrimonio \\ Construido (Posgrado) \\ - Metodología para la Intervención en el Patrimonio \\ Arquitectónico (Posgrado)
}

\section{GALICIA}

- Patología y Restauración Arquitectónicas (Máster)

MADRID

- Conservación y Restauración del Patrimonio Arquitectónico y Urbano (Máster)

- Teoría, Historia y Documentación (Especialización)

- Construcción (Especialización)

- Patología de la Edificación y Técnicas de Intervención (Especialización)

- Restauración y Rehabilitación en la Edificación (Especialización)

- Restauración Arquitectónica (Máster)

- Teoría, Historia, Legislación e Intervención en la Rehabilitación (Especialización)

- Máster de Restauración y Rehabilitación del Patrimonio

- Máster en Gestión de Edificación y Rehabilitación

PAÍS VASCO

- Patrimonio Arquitectónico (Máster)

\section{VALENCIA}

- Máster en Conservación del Patrimonio Arquitectónico

Organiza: Universidad de Sevilla, Consejería de Cultura de la Junta de Andalucía (Instituto Andaluz del Patrimonio Histórico).

HISTÓRICO

\section{Universidad de Sevilla}

Objetivos: Cualificar tanto a nivel teórico como práctico a los profesionales en el conocimiento, la interpretación y la intervención sobre el Patrimonio Histórico, de acuerdo con criterios, métodos y técnicas actualizados y en sintonía con las directrices de los organismos tutelares de los Bienes Culturales.
Destinatarios: Preferentemente Arquitectos y Licenciados en Geografía e Historia. Excepcionalmente, Arquitectos e Ingenieros Técnicos con experiencia y alumnos de P.F.C. matriculados en una Escuela Técnica Superior de Arquitectura. 
Duración: 500 horas (última edición: febrero de 2000 - marzo de 2001.

\section{Contenidos:}

- I Contexto administrativo del trabajo patrimonial (patrimonio histórico: introducción a sus conceptos generales;estructura administrativa y de gestión; legislación y planificación; la protección del patrimonio histórico; inventarios y catálogos; planeamiento especial).

- Il Contorno cultural del trabajo patrimonial (Nivel teórico: lo construido como patrimonio: encuentro entre lo arquitectónico y lo patrimonial; de la arquitectura al patrimonio y viceversa. Nivel interpretativo: revisión de la producción patrimonial en España: 1980-1999; relevancia de los ejemplos-modelo; resumen crítico de los resultados. Nivel proyectual: el proyecto como instrumento de la modificación; niveles de la modificación: conservación, transformación, invención; estrategias proyectuales).

- III Enfoque interdisciplinar del conocimiento patrimonial (Nivel teórico: el pensamiento de la complejidad; tradición como memoria. Nivel interpretativo: revisión de los niveles de información y valoración: disciplinas comprometidas; arqueología; restauración de bienes muebles; etnología; museología/museografía; historia/narración; técnicas de análisis y diagnóstico; representar el patrimonio; urbanística; lo objetual, lo arquitectónico, lo urbano y lo territorial. Nivel proyectual: el proyecto como intervención; escritura, medio e intervención; del objeto al ambiente)

- IV Interpretación histórica como metasignificación (el signo de lo patrimonial; crítica como puesta en valor de lo patrimonial; historiografía; tradiciónrenovación; acción-reflexión; pasado- presente; hermeneútica; interpretación de un fragmento de ciudad como base del proyecto de intervención)

- V Valoración como condición de la instrumentación. (proyecto de conservación, proyecto de modificación valores de lo patrimonial y acciones de conservación; materialidad de lo patrimonial: de la conservación preventiva al mantenimiento; tratamientos, compatibilidades e incompatibilidades; lo patrimonial como ecología de lo construido; seminarios de gestión del patrimonio: conservación, protección, información, difusión y puesta en valor, patrimonio; desarrollo y rentabilidad social; turismo cultural)

- VI El proyecto patrimonial (proyectar el patrimonio; fragmento y generalidad; escala del proyecto; proyecto de concreción: materialidad y ambiente; Musealización; Dinamización; Instrumentación).

Información:

\section{Secretaría del MARPH}

Instituto Andaluz del Patrimonio Histórico

Isla de la Cartuja, I. Edificio B, $2^{\text {a }}$ planta

41092 Sevilla

Tel.: 955037045

Fax : 95503700

Web: www.iaph.junta-andalucia.es

Correo-e: formac@iaph.junta-andalucia.es
MÁSTER INTERNACIONAL EN REHABILITACIÓN DEL PATRIMONIO EDIFICADO

Centro Internacional para la Conservación del Patrimonio (CICOP)

Destinatarios: Graduados de primer o segundo ciclo universitario de cualquier universidad española con relación a las áreas multidisciplinares que abarca el máster. También podrán acceder titulados por cualquier facultad o escuela técnica extranjera equiparable a las anteriores, pudiendo matricularse de áreas sueltas.

\section{Contenidos:}

Tecnología de la piedra; Tecnología de la madera; Criterios en la restauración de bienes muebles; Restauración de jardines históricos; Metodología para la restauración y la rehabilitación; Restauración y conservación de pintura mural; Gestión y proyectos restauración y conservación del patrimonio diverso; Tecnología de la restauración; Antecedentes históricos en el patrimonio construido; Area de seguridad y salud en las obras de rehabilitación.

Información:

Centro Internacional para la Conservación del Patrimonio Casa de los Capitanes Generales

Carrera, I

3820। La Laguna, Tenerife

Tel.: $92260 \mid$ |67-922 60। 100, ext. 337

Fax: 922601167

Web: www.cicop.com

Correo-e: iicp@teide.net

\section{MÁSTER UNIVERSITARIO EN RESTAURACIÓN ARQUITECTÓNICA \\ Universidad de Valladolid}

Objetivos: La formación de profesionales y titulados universitarios de segundo ciclo, de modo que se encuentren, a su conclusión, en óptimas condiciones para entender, apreciar, restaurar y conservar edificios y obras de arte de interés general y más específicamente arquitectónico, de los conjuntos urbanos y rurales, con especial atención a los referidos al ámbito histórico geográfico de la actual Comunidad de Castilla y León.

Organiza: Universidad de Valladolid, Escuela Técnica Superior de Arquitectura. Con la colaboración de la Consejería de Educación y Cultura de la Junta de Castilla y León.

Destinatarios: Titulados superiores: Arquitecto, ingeniero o licenciado universitario.

Duración: 510 horas (última edición 16/10/00 - 24/ 06//02).

Contenidos:

- I Anualidad: Análisis y valoración del patrimonio 
I; Proyectos de restauración l; Ejecución de obras I; El debate contemporáneo en la restauración arquitectónica I; Introducción a las ciencias auxiliares l: Arqueología y Museología; Introducción a las ciencias auxiliares II: Restauración de bienes muebles y elementos ornamentales del patrimonio arquitectónico; Procedimientos técnicos para la restauración I; Procedimientos técnicos para la restauración II.

- $2^{a}$ Anualidad: Análisis y valoración del patrimonio II; Proyectos de restauración II; Ejecución de obras II; El debate contemporáneo en la restauración arquitectónica II; Teoría e historia de la restauración arquitectónica; Técnicas de análisis gráfico del patrimonio; Técnicas de análisis de materiales y diagnóstico; Historia de los procesos constructivos; Procedimientos legales y administrativos para la conservación y restauración del patrimonio histórico; Protección e intervención en la ciudad histórica

Información:

\section{Teresa Cendón González}

E.T.S. de Arquitectura

Avda. de Salamanca s/n

47014 Valladolid

Tel.: 983423646

Fax: 983423425

Web: www.uva.es

Correo-e: restaura@modulor.arq.uva.es

\section{ESPECIALISTA UNIVERSITARIO EN CIENCIAS AUXILIARES PARA LA RESTAURACIÓN DEL PATRIMONIO HISTÓRICO \\ Universidad de Valladolid}

Objetivos: La formación de profesionales, licenciados y diplomados universitarios de modo que se encuentren, a su conclusión, en óptimas condiciones para el conocimiento de los procedimientos científicos y tecnológicos puestos al servicio de la conservación de la cultura material.

Organiza: Universidad de Valladolid, Escuela Técnica Superior de Arquitectura. Con la colaboración de la Consejería de Educación y Cultura de la Junta de Castilla y León.

Destinatarios: Arquitecto, arquitecto técnico, ingeniero, ingeniero técnico, o licenciados o diplomados.

Duración: 220 horas (última edición: Octubre de 2000 a junio de 2002).

\section{Contenidos:}

- Ia Anualidad: Análisis y valoración del patrimonio I; Introducción a las ciencias auxiliares I: Arqueología y museología; Introducción a las ciencias auxiliares II: Restauración de bienes muebles y elementos ornamentales del patrimonio arquitectónico.
- $2^{\text {a }}$ Anualidad: Análisis y valoración del patrimonio II; El debate contemporáneo en la restauración arquitectónica; Procedimientos legales y administrativos para la conservación y restauración del patrimonio histórico; Técnicas de análisis de materiales y diagnóstico.

\section{Información:}

\section{Teresa Cendón González}

E.T.S. de Arquitectura

Avda. Salamanca, s/n

47014 VALLADOLID

Tel.: 983423646

Fax: 983423425

Web: www.uva.es

Correo-e: restaura@modulor.arq.uva.es

\section{ESPECIALISTA UNIVERSITARIO EN TÉCNICAS Y PROCEDIMIENTOS PARA LA RESTAURACIÓN DEL PATRIMONIO HISTÓRICO \\ Universidad de Valladolid}

Objetivos: La formación de profesionales, licenciados y titulados universitarios, de modo que se encuentren, a su conclusión, en óptimas condiciones para conocer, ponderar y valorar el conjunto de procedimientos técnicos empleados en la conservación y restauración del patrimonio histórico.

Organiza: Universidad de Valladolid, Escuela Técnica Superior de Arquitectura. Con la colaboración de la Consejería de Educación y Cultura de la Junta de Castilla y León.

Destinatarios: Arquitecto, arquitecto técnico, ingeniero, ingeniero técnico, licenciados o diplomados universitarios.

Duración: 220 horas (última edición: Octubre 2000junio 2002).

\section{Contenidos:}

- I a Anualidad: Procedimientos técnicos para la restauración I y II; Ejecución de obras I.

- $2^{a}$ Anualidad: El debate contemporáneo en la restauración arquitectónica; Ejecución de obras II; Técnicas de análisis de materiales y diagnóstico; Historia de los procesos constructivos; Procedimientos legales y administrativos para la conservación y restauración del patrimonio histórico.

Información:

\section{Teresa Cendón González}

E.T.S. de Arquitectura

Avda. de Salamanca, s/n

470 I 4 VALLADOLID

Tel.: 983423646

Fax: 983423425

Web: www.uva.es

Correo-e: restaura@modulor.arq.uva.es 
ESPECIALISTA UNIVERSITARIO EN TEORÍA Y ANÁLISIS DEL PATRIMONIO HISTÓRICO

Universidad de Valladolid

Objetivos: La formación de profesionales, licenciados y diplomados universitarios de modo que se encuentren, a su conclusión, en óptimas condiciones para conocer la evolución del pensamiento y de los instrumentos teóricos y legales que se vienen produciendo en el campo de la restauración del Patrimonio Histórico.

Organiza: Universidad de Valladolid, Escuela Técnica Superior de Arquitectura. Con la colaboración de la Consejería de Educación y Cultura de la Junta de Castilla y León.

Destinatarios: Arquitecto, arquitecto técnico, ingeniero, ingeniero técnico, licenciados o diplomados universitarios,

Duración: 220 horas (última edición: octubre de 200 l-junio de 2002).

\section{Contenidos:}

Teoría e historia de la restauración arquitectónica; Análisis y valoración del patrimonio; Técnicas de análisis de materiales y diagnóstico; Historia de los procesos constructivos; Procedimientos legales y administrativos para la conservación y restauración del patrimonio histórico; Protección e intervención en la ciudad histórica; El debate contemporáneo en la restauración arquitectónica.

Información:

\section{Teresa Cendón González}

E.T.S. de Arquitectura

Avda. de Salamanca, s/n

470। 4 VALLADOLID

Tel.: 983423646

Fax: 983423425

Web: www.uva.es

Correo-e: restaura@modulor.arq.uva.es

\section{EL PROYECTO: APROXIMACIONES A LA ARQUITECTURA DESDE EL MEDIO AMBIENTE HISTÓRICO Y SOCIAL (MÁSTER) Universidad Politécnica de Cataluña}

Objetivos: Preparar (educar) técnicos-asesores, consultores medioambientales, y/o diseñadores de entornos históricos. El papel del arquitecto será fundamental en el momento que se realicen estudios, informes o auditorias de impacto ambiental. El trabajo en los próximos dos años se enfoca en los trabajos concretos que tendrá este nuevo técnico o profesional.

Organiza: Universidad Politécnica de Cataluña, Departamento de Proyectos Arquitectónicos.
Duración: 460 horas (última edición: 04/10/2000 30/06/200I).

\section{Contenidos:}

- Asignaturas obligatorias: Arquitectura y forma urbana; Taller de proyecto I: variaciones temáticas europeas; Metodologías interdisciplinarias de intervención en el medio rural; Evaluación de los sistemas de información geográfica y arquitectónica: redes telemáticas y modelos informáticos; Taller de proyectos II: proyectar en el tiempo; Metodologías de evaluación histórico -culturales de la arquitectura.

- Seminarios: Dimensiones arqueológicas; Dimensiones Histórico Culturales; Dimensiones constructivas y energéticas; Síntesis Arquitectónica.

Información:

Fundació Politècnica de Catalunya

Edifici Vèrtex

PI. Eusebi Güell, 6

08034 Barcelona

Marc Voltas

Tel.: $93401 \mid 852$

Fax: 934011873

Web: www.fpc.upc.es

Correo-e: infoarq@fpc.upc.es

HISTORIA, ARTE, ARQUITECTURA Y CIUDAD (MÁSTER) Universidad Politécnica de Cataluña

Objetivos: Especialización funcional en el campo del análisis del arte, arquitectura y la ciudad. A través de estudios monográficos se accede al conocimiento específico de los momentos claves de la cultura artística y arquitectura occidental.

Organiza: Universidad Politécnica de Cataluña, Departamento de Composición Arquitectónica.

Duración: 540 horas (última edición: 02/10/0030/06/0I).

\section{Contenidos:}

Arte de postguerra (USA, Europa); La educación de la forma en los Vhutemas y en la Bauhaus; Teatro y ciudad; Habitar, nímesis, cultura; Historiografía del arte; Teoría de la arquitectura II; Teoría de la arquitectura I; Historiografia de la arquitectura; Josep Lluis Sert; Estructura del estudio de mercado; La técnica en la arquitectura contemporánea; El concepto de "realismo" (sachlicheit) en arquitectura: H.P. Berlage; O.Wagner; H. Muthersius; Antoni Gaudí 1852-1926; La ciudad europea y el urbanismo contemporáneo; Ciclo de conferencias: arquitectura y política; Arquitectura moderna y crítica en Latinoamérica; Taller; Mitos y arquitectura en el mundo antiguo occidental.

Información:

Fundació Politècnica de Catalunya 
Edifici Vèrtex

PI. Eusebi Güell, 6

08034 Barcelona

Marc Voltas

Tel.: 934011852

Fax: 934011873

Web: www.fpc.upc.es

Correo-e: infoarq@fpc.upc.es

\section{RESTAURACIÓN DE MONUMENTOS DE} ARQUITECTURA (MÁSTER)

\section{Universidad Politécnica de Cataluña}

Objetivos: Preparar técnicos con criterio para valorar el grado de importancia y la especificidad de los monumentos y edificios históricos y de los conjuntos histórico- artísticos por tal de decidir la forma más correcta de intervención. Reconocer la importancia de las patologías para poder intervenir en la restauración de los monumentos de forma respetuosa y con las técnicas más adecuadas.

Organiza: Universidad Politécnica de Cataluña, Departamento de Infraestructura del Transporte y del Territorio.

Duración: 450 horas (última edición: 20/10/0025/06/02).

\section{Contenidos:}

Historia de la restauración; Conocimiento cualitativo de los materiales y de las técnicas constructivas; Historia y arquitectura; Arqueología y arquitectura; Patrimonio industrial y arquitectura; Historia urbana; Patologías constructivas I; Trabajos de análisis arquitectónico, urbanístico e histórico; Antoni Gaudí por dentro; Teoría de la intervención arquitectónica; Proyecto de intervención; Patologías constructivas II; Fotogrametría arquitectónica; La gestión del patrimonio arquitectónico; Formas de intervención en los centros históricos.

Información:

Fundació Politècnica de Catalunya

Edifici Vèrtex

PI. Eusebi Güell, 6

08034 Barcelona

Marc Voltas

Tel.: 934011852

Fax: 934011873

Web: www.fpc.upc.es

Correo-e: infoarq@fpc.upc.es

ARQUITECTURA Y ARTESANÍA (POSGRADO)

Universidad Politécnica de Cataluña

Organiza: Universidad Politécnica de Cataluña, Departamento de Expresión Gráfica Arquitectónica I.
Duración: 180 horas (última edición: 05/02/0103/05/01).

\section{Contenidos:}

Seminario teórico: "sobre la arquitectura y otras herramientas"; Lecciones teóricas; Ciclo de conferencias; Análisis de edificios; Talleres; Visita a talleres profesionales.

Información:

Fundació Politècnica de Catalunya

Edifici Vèrtex

PI. Eusebi Güell, 6

08034 Barcelona

Marta López

Tel.: 934011 971

Fax: 934011873

Web: www.fpc.upc.es

Correo-e: marta@fpc.upc.es

FORMAS DE ANÁLISIS E INTERVENCIÓN EN EL PATRIMONIO CONSTRUIDO (POSGRADO)

\section{Universidad Politécnica de Cataluña}

Organiza: Universidad Politécnica de Cataluña, Departamento de Infraestructura del Transporte y del Territorio.

Duración: 370 horas (última edición: 20/10/0020/02/01).

\section{Contenidos:}

Historia de la restauración; Conocimiento cualitativo de los materiales y de las técnicas constructivas; Patologías constructivas I; Trabajos de análisis arquitectónico, urbanístico e histórico; Antoni Gaudí por dentro; Teoría de la intervención arquitectónica; Proyecto de intervención; Patologías constructivas II; Fotogrametría arquitectónica; Formas de intervención en los centros históricos.

\section{Información:}

\section{Fundació Politècnica de Catalunya}

Edifici Vèrtex

Pl. Eusebi Güell, 6

08034 Barcelona

Marc Voltas

Tel.: 934011852

Fax: 934011873

Web: www.fpc.upc.es

Correo-e: infoarq@fpc.upc.es

METODOLOGÍA PARA LA INTERVENCIÓN EN EL PATRIMONIO ARQUITECTÓNICO (POSGRADO) Universidad Politécnica de Cataluña

Objetivos: El principal objetivo de formación es transmitir al alumno una metodología de actuación 
que, partiendo de unos conocimientos académicos y profesionales, en general, fragmentados, organice las faenas profesionales relacionadas con la intervención en el Patrimonio con los criterios reconocidos entre los especialistas como más avanzados y fruto de las más elaboradas reflexiones colectivas de los últimos años. Un segundo objetivo tiene como misión dar unas bases de conocimientos que generalmente no son habituales en los currículos académicos de los alumnos. Un tercer objetivo busca que la experiencia directa sobre las obras visitadas reafirme la asimilación de todos los contenidos, tanto teóricos como los relacionados con la práctica profesional.

Organiza: Universidad Politécnica de Cataluña, Departamento de Construcciones Arquitectónicas I.

Duración: 150 horas (última edición: 02/02/0130/03/0I).

\section{Contenidos:}

Teoría y método de la intervención en el patrimonio; Construcción e intervención en la historia; Experiencia directa de obras en el patrimonio.

Información:

\section{Fundació Politècnica de Catalunya}

Edifici Vèrtex

PI. Eusebi Güell, 6

08034 Barcelona

Marc Voltas

Tel.: 934011852

Fax: 934011873

Web: www.fpc.upc.es

Correo-e: infoarq@fpc.upc.es

\section{PATOLOGÍA Y RESTAURACIÓN ARQUITECTÓNICAS (MÁSTER) \\ Universidad de la Coruña}

Objetivo: Formación de técnicos que se especialicen en el estudio, reconocimiento, diagnóstico y reparación de los daños que pueda sufrir un edificio, así como la intervención razonada en el patrimonio arquitectónico.

Junto con la formación en técnicas, los alumnos profundizarán en el conocimiento cultural, histórico y espacial del patrimonio, de forma que aborden los temas de intervención desde planteamientos globales, que les permitan resolver los temas prácticos con sensibilidad y acierto.

Organiza: Departamento de Construcciones Arquitectónicas de la Universidad La Coruña

Destinatarios: Arquitectos y profesionales, que con una formación técnica o humanística confluyan en el campo de la restauración y rehabilitación: arqueólogos, restauradores, ingenieros y aparejadores.
Duración: 525 horas durante un año, de octubre a junio.

\section{Contenidos:}

- Área I. Teoría, historia y criterios de intervención en el patrimonio arquitectónico (Teoría de la conservación del patrimonio; Historia de la construcción del patrimonio; Legislación sobre rehabilitación y restauración; Criterios de intervención en el patrimonio).

- Área II. Territorio y paisaje como patrimonio (EI patrimonio del territorio y de la ciudad; Integración y rehabilitación de jardines; Comarcas y comercialización de Galicia; Urbanización y ruralización de Galicia; Rehabilitación de los bordes marítimos)

- Área III. Patología, conservación y reparación de edificios (La patología y los estudios patológicos; Técnicas de estudios previos y toma de datos; Patología y reparación de cimentaciones y obras de fábrica; Patología y reparación de estructuras; Patología y reparación de fachadas, cerramientos y acabados; Técnicas de intervención en la restauración).

- Área IV. Acondicionamiento e instalaciones en la rehabilitación (La rehabilitación ambiental hidrotérmica, luminosa y acústica; La rehabilitación de las instalaciones de acondicionamiento; La rehabilitación de las instalaciones eléctricas e iluminación; La rehabilitación de las instalaciones de fontanería y saneamiento; Los sistemas de protección contra incendios en la rehabilitación; El acondicionamiento y aislamiento acústico en la rehabilitación).

Información:

\section{E.T.S. de Arquitectura}

Departamento de Construcciones Arquitectónicas

Campus da Zapateira

|507| A Coruña

Tel.: 98| 167000 , ext. 5330

Fax: 981 167051

Web: www.ud.es/uep

Correo-e: restaura@udc.es

\section{CONSERVACIÓN Y RESTAURACIÓN DEL PATRIMONIO ARQUITECTÓNICO Y URBANO (MÁSTER) \\ Universidad Politécnica de Madrid}

Objetivo: Proporcionar una formación teórico práctica a arquitectos, historiadores, arqueólogos, ingenieros y otros titulados que estén interesados en todo lo que concierne el patrimonio Arquitectónico, desde sus aspectos legales e históricos, hasta la elaboración del proyecto de conservación y/o restauración, pasando necesariamente por el análisis constructivo y material del mismo.

Organiza: Universidad Politécnica de Madrid, Escuela Técnica Superior de Arquitectura de Madrid a través del Instituto Juan de Herrera.

Destinatario: Titulados, licenciados y estudiantes del último curso o Proyecto Fin de Carrera. 
Duración: 500 horas, de febrero a junio.

\section{Contenidos:}

- I. Teoría, historia y documentación (La evolución de la teoría de la restauración en los siglos XIX y XX; Historia de la Restauración; Administración y legislación del patrimonio; Tipos arquitectónicos monumentales; Áreas históricas; Jardines históricos; Metodología de análisis previos y documentación).

- II. Construcción (Materiales y sistemas constructivos históricos; Materiales pétreos; Mecánica de las fábricas; Revestimientos y artes decorativas; El suelo; Instalaciones en los edificios históricos; Construcciones de tierra; Estructuras de madera; Estructuras metálicas históricas; Luminotecnia e iluminación de monumentos).

- III. Taller de proyectos (Taller de proyectos; Tutorías de proyectos; Clases de aplicación; Campo cultural del monumento y proyecto de intervención arquitectónica; Valores patrimoniales a restituir y proyecto arquitectónico; El proyecto de articulación de lo nuevo y lo antiguo; Visitas de obras y edificios; Talleres).

Información:

E.T.S. de Arquitectura de Madrid

Aula Juan de Herrera

Avda. Juan de Herrera, 4

28040 Madrid

Lola Bustillos

Tel.: 913366539

Fax. 91544248 !

Web: www.aq.upm.es

Correo-e: bustillo@aq.upm.es

\section{TEORÍA, HISTORIA Y DOCUMENTACIÓN}

(ESPECIALIZACIÓN)

\section{Universidad Politécnica de Madrid}

Oferta modular del Máster de Conservación y Restauración del Patrimonio Arquitectónico y Urbano organizado por la Universidad Politécnica de Madrid, Escuela Técnica Superior de Arquitectura de Madrid a través del Instituto Juan de Herrera.

Destinatario: Titulados, licenciados y estudiantes del último curso o Proyecto Fin de Carrera.

\section{Contenidos:}

- I. Teoría, historia y documentación (La evolución de la teoría de la restauración en los siglos XIX y XX; Historia de la Restauración; Administración y legislación del patrimonio; Tipos arquitectónicos monumentales; Áreas históricas; Jardines históricos; Metodología de análisis previos y documentación).

- II. Taller de proyectos (Taller de proyectos; Tutorías de proyectos; Clases de aplicación; Campo cultural del monumento y proyecto de intervención arquitectónica; Valores patrimoniales a restituir y proyecto arquitectónico; El proyecto de articulación de lo nuevo y lo antiguo; Visitas de obras y edificios; Talleres).
Información:

E.T.S. de Arquitectura de Madrid

Aula Juan de Herrera

Avda. Juan de Herrera, 4

28040 Madrid

Lola Bustillos

Tel.: 913366539

Fax. 915442481

Web: www.aq.upm.es

Correo-e: bustillo@aq.upm.es

\section{CONSTRUCCIÓN (ESPECIALIZACIÓN) \\ Universidad Politécnica de Madrid}

Oferta modular del Máster de Conservación y Restauración del Patrimonio Arquitectónico y Urbano organizado por la Universidad Politécnica de Madrid, Escuela Técnica Superior de Arquitectura de Madrid a través del Instituto Juan de Herrera

Destinatario: Titulados, licenciados y estudiantes del último curso o Proyecto Fin de Carrera.

\section{Contenidos:}

- I. Construcción (Materiales y sistemas constructivos históricos; Materiales pétreos; Mecánica de las fábricas; Revestimientos y artes decorativas; El suelo; Instalaciones en los edificios históricos; Construcciones de tierra; Estructuras de madera; Estructuras metálicas históricas; Luminotécnia e iluminación de monumentos).

- I. Taller de proyectos (Taller de proyectos; Tutorías de proyectos; Clases de aplicación; Campo cultural del monumento y proyecto de intervención arquitectónica; Valores patrimoniales a restituir y proyecto arquitectónico; El proyecto de articulación de lo nuevo y lo antiguo; Visitas de obras y edificios; Talleres).

Información:

\section{E.T.S. de Arquitectura de Madrid}

Aula Juan de Herrera

Avda. Juan de Herrera, 4

28040 Madrid

Lola Bustillos

Tel.: 913366539

Fax. 915442481

Web: www.aq.upm.es

Correo-e: bustillo@aq.upm.es

\section{PATOLOGÍA DE LA EDIFICACIÓN Y TÉCNICAS DE INTERVENCIÓN (ESPECIALIZACIÓN) \\ Universidad Politécnica de Madrid}

Objetivos: Formación teórica y práctica en temas relacionados con la patología de elementos de la edificación y la conservación. Rehabilitación y restauración de los mismos. 
Organiza: Universidad Politécnica de Madrid. Dpto. de Construcción y Tecnología Arquitectónicas.

Dirigido: Titulados universitarios.

Duración: 350 horas (última edición: enero- julio de 200I).

\section{Contenidos:}

Estudios previos; Obras de fábrica; Patología y acondicionamiento higrotérmico; Las humedades y su tratamiento; Cimentaciones, realces y apeos; Recuperación de estructuras de madera; Estructuras de hormigón y metálicas; Instalaciones eléctricas y de alumbrado; Revocos y pinturas; Cerramientos y acabados; La acústica en la rehabilitación; Cubiertas; La fontanería en la rehabilitación.

Información:

\section{E.T.S. de Arquitectura}

Dpto. de Construcción y Tecnología Arquitectónicas

Ciudad Universitaria

28040 Madrid

Tel.: 913366560

Fax: 913366560

Web: www.upm.es

Correo-e: restauracion@aq.upm.es

\section{RESTAURACIÓN Y REHABILITACIÓN EN LA EDIFICACIÓN (ESPECIALIZACIÓN) \\ Universidad Politécnica de Madrid}

Objetivos: Formación de especialistas cualificados en la concepción y la problemática de los temas constructivos relacionados con la restauración y la rehabilitación de edificios y en la gestión del patrimonio inmobiliario.

Organiza: Universidad Politécnica de Madrid, E.U. de Arquitectura Técnica y Fundación Escuela de la Edificación.

Dirigido: Titulados Universitarios.

Duración: 150 horas (última edición: marzo-junio de 2002).

\section{Contenidos:}

Conceptos generales: criterios de intervención; toma de datos; metrología, topografía y fotogrametría. La restauración monumental: marco jurídico; la Real Academia y las Comisiones de Patrimonio; aspectos sociológicos en la rehabilitación; la coordinación entre el historiador, el arqueólogo y los técnicos; la declaración de ruina. Introducción a la gestión del patrimonio urbano. Patología, tratamiento y reparación de cimentaciones, estructuras de hormigón, metálicas y de madera, cubiertas, fachadas. Procesos. Intervenciones y reparaciones. El tratamiento acústico y el aislamiento térmico. La iluminación. El incen- dio. La evacuación en edificios antiguos. La piedra. Los revocos. Techumbres y entramados de madera. Vidrieras. Derribos y demoliciones. Apeos y apuntalamientos. La fachada cáscara.

Información:

Fundación Escuela de la Edificación

C/ Maestro Victoria, 3

28013 Madrid

Tel.: 915318700

Fax: 915313169

Web: www.upm.es

Correo-e: felipe34@arrakis.es

\section{RESTAURACIÓN ARQUITECTÓNICA (MÁSTER) \\ Universidad Politécnica de Madrid}

Objetivos: Formación teórica y práctica en temas de restauración y rehabilitación arquitectónica, de gran actualidad tanto en el mundo cultural (patrimonio arquitectónico) como en el inmobiliario, que permite adquirir conocimiento profundo en una temática de interés e importancia crecientes.

Organiza: Universidad Politécnica de Madrid, Dpto. de Construcción y Tecnología Arquitectónicas.

Dirigido: Titulados Universitarios.

Duración: 600 horas (última edición: enero - junio de 200I).

\section{Contenidos:}

Patología de la edificación y técnicas de intervención; Teoría, historia, legislación e intervención en la rehabilitación.

Este programa de máster comprende también dos cursos de especialización anteriores: "Teoría Historia, Legislación e Intervención en la Rehabilitación" y "Patología de la Edificación y Técnicas de Intervención".

Información:

\section{E.T.S. de Arquitectura}

Dpto. de Construcción y Tecnología Arquitectónicas

Ciudad Universitaria

28040 Madrid

Tel.: 913366560

Fax: 913366560

Web: www.upm.es

Correo-e: restauracion@aq.upm.es

TEORÍA, HISTORIA, LEGISLACIÓN E INTERVENCIÓN EN LA REHABILITACIÓN (ESPECIALIZACIÓN)

Universidad Politécnica de Madrid

Objetivos: Formación teórica y práctica en aspectos fundamentales de la rehabilitación. 
Organiza: Universidad Politécnica de Madrid, Dpto. de Construcción y Tecnología Arquitectónicas.

Dirigido: Titulados Universitarios.

Duración: 150 horas (última edición: enero - junio de 200I).

\section{Contenidos:}

A) Teoría: programa por módulos: Teoría; Historia de la restauración; Historia del sistema constructivo; Incidencia de la arqueología; Valoración de las edificaciones; El entorno urbano del monumento.

B) Práctica por temas: Propuesta gráica; Crítica; Informe; Toma de datos históricos y constructivos; Proyecto.

\section{Información:}

\section{E.T.S. de Arquitectura}

Dpto. de Construcción y Tecnología Arquitectónicas

Ciudad Universitaria

28040 Madrid

Tel.: 913366560

Fax: 913366560

Web: www.upm.es

Correo-e: restauracion@aq.upm.es

\section{MÁSTER DE RESTAURACIÓN Y REHABILITACIÓN DEL PATRIMONIO}

\section{Universidad de Alcalá}

Objetivos: Impartir una enseñanza pluridisciplinar que conciba el proceso de intervención en el patrimonio en su conjunto y permita integrar los cambios en los métodos de proyectar con los nuevos medios de trabajo, así como extender los conceptos de la intervención a todos los elementos que conforman el patrimonio.

Organiza: Universidad de Alcalá a través del Instituto Español de Arquitectura y la Fundación General de la Universidad de Alcalá.

Destinatarios: Licenciados y titulados en las diferentes especialidades que intervienen en los procesos de consolidación, restauración y conservación del patrimonio arquitectónico: Arquitectos, Arquitectos Técnicos con 5 años de experiencia profesional, Arqueólogos, Geógrafos, Historiadores, Historiadores del Arte, Ingenieros, Licenciados en Bellas Artes, Químicos, Restauradores, Abogados y Economistas.

Duración: 800 horas (última edición 20/10/0022/|2/0|).

\section{Contenidos:}

- Área I: Teoría e historia de la restauración (Introducción a la teoría y práctica restauradora; Historia de la restauración, orígenes y desarrollo; Archivos de patrimonio y análisis histórico-tipológico; Teoría y metodología de la intervención arqueológica)
- Área 2: El proyecto de conservación e intervención (La restauración como proyecto de la arquitectura; Patrimonio arquitectónico y territorio; Patrimonio histórico y medio natural; El patrimonio de la Iglesia)

- Área 3: Procedimientos y técnicas constructivas del patrimonio (La estructura en la historia de la arquitectura funcional, diagnóstico y reparación; Instalaciones y tecnologías de aplicación al monumento; Madera; Tratamiento y conservación de la piedra)

- Área 4: Técnicas de restauración y conservación (Restauración y conservación de obras muebles, escultura y pintura; Arcillas y materiales cerámicos; Revestimientos: estucos, revocos y pinturas; Vidrio y cerámica histórica)

- Área 5: Gestión de patrimonio (Gestión económica del proyecto; Valoración de los proyectos de restauración; Métodos y técnicas de estudios previos y documentación del patrimonio; Estrategias económicas del patrimonio histórico, legislación y jurisprudencia)

Información:

Instituto Español de Arquitectura. Colegio Trinitarios

Calle Trinidad, I

2880I Alcalá de Henares, Madrid

Tel.: 918855 276-918 855312

Fax: 918855276

Web: www.masterpatrimonio.edu

Correo-e: master.patrimonio@alcala.es

\section{MÁSTER EN GESTIÓN DE EDIFICACIÓN Y REHABILITACIÓN}

\section{Fundación Antonio Camuñas}

Objetivos: Capacitar al alumno para el acceso a puestos de responsabilidad en la dirección de las empresas de edificación. También les prepara para asumir una función destacada en la creación y desarrollo de nuevas empresas especializadas en el mundo de la rehabilitación.

Organiza: Fundación Antonio Camuñas, Centro Superior de Arquitectura.

Destinatarios: Arquitectos e Ingenieros.

Duración: 450 horas lectivas y 1000 horas de prácticas remuneradas (última edición octubre 1999 febrero 200I)

\section{Contenidos:}

- Áreas de ciencias empresariales

- Área jurídico-empresarial

- Área de gestión empresarial de la construcción

- Área de rehabilitación (Introducción al patrimonio y la rehabilitación; características sociales de la rehabilitación; Control de riesgo: precio, plazo; Proyecto constructivo; perfil del jefe de obra de rehabilitación; Tecnologías especiales: cimentación, estructuras, cubiertas; Fachadas: GRC y prefabricación; Instalaciones; Electrificación; Técnicas de industrialización, apeos, andamios y prevención; Casos reañes) 
Información:

\section{Fundación Antonio Camuñas}

Centro Superior de Arquitectura

Alameda, 14

28014 Madrid

Tel.: 914203864

Fax: 914201039

Web: www.fundacioncamunas.es

Correo-e: csa@fundacioncamuna.es

\section{PATRIMONIO ARQUITECTÓNICO (MÁSTER) Universidad del País Vasco}

Organiza: Universidad del País Vasco, Departamentos de Física Aplicada I, Matemática Aplicada, Arquitectura. Escuela Técnica Superior de Arquitectura.

Destinatarios: Licenciatura, Ingeniería Industrial, Arquitectura. Excepcionalmente Arquitectura Técnica e Ingeniería Técnica.

Duración: 864 horas (última edición: 29/10/2000 |5/09/200|).

\section{Contenidos:}

Conservación, restauración y rehabilitación; Historia de la restauración; El proyecto de intervención en patrimonio arquitectónico; Gestión, normativa y valoración del proyecto de intervención; Tipos estructurales y sistemas constructivos; Patología en construcciones del patrimonio arquitectónico; Técnicas de análisis en patrimonio arquitectónico; Técnicas de intervención estructural; Acondicionamiento e instalaciones en patrimonio arquitectónico; Conservación y tratamiento de los materiales; Aplicaciones informáticas en patrimonio arquitectónico; El patrimonio como un factor de desarrollo: El caso de los paradores nacionales de turismo.

Información:

\section{E.T.S. de Arquitectura}

Dpto. Física Aplicada I

Plaza de Oñati, 2

20009 Donostia-San Sebastián, Gipuzkoa

Tel.: 943015894

Fax: 943219727

Web: www.ehu.es

Correo-e: wupsabes@sa.ehu.es-uazaiirm@sa.ehu.es

\section{MÁSTER EN CONSERVACIÓN DEL PATRIMONIO ARQUITECTÓNICO}

\section{Universidad Politécnica de Valencia}

Objetivos: El V Máster en Conservación del Patrimonio Arquitectónico de la Universidad Politécnica de Valencia mantiene la orientación de los anteriores cursos desarrollando cuatro líneas básicas:

- DOCENTE, a través de la transmisión de conocimientos teóricos y prácticos de materias directa- mente relacionadas con el campo conservación de la arquitectura histórica.

- INVESTIGACIÓN, mediante la realización de estudios, ensayos, etc., aplicados a la realidad patrimonial intervinientes en los procesos de conservación de forma que permitan tanto un mayor conocimiento de los propios bienes culturales arquitectónicos como de las técnicas y metodologías de análisis y de intervención.

- PROFESIONAL, dirigido directamente a la preparación de técnicos cualificados que formen un cuadro de operadores que compongan la respuesta a las necesidades que el desarrollo social y cultural tiene planteadas sobre la recuperación y conservación del patrimonio arquitectónico de interés histórico.

- INSTITUCIONAL, mediante el desarrollo de estudios, trabajos o consultas, en temas específicos de interés para la sociedad, en relación con el patrimonio valenciano, a propuesta y en colaboración con los técnicos de los organismos competentes y que sean compatibles con la programación de los cursos.

Organiza: Universidad Politécnica de Valencia, Escuela de Arquitectura Técnica.

Destinatarios: Titulados universitarios Arquitectos o Arquitectos Técnicos que den respuesta a las necesidades que el desarrollo social y cultural tiene planteadas sobre la recuperación y conservación del patrimonio arquitectónico.

Duración: 600 horas (última edición: 10/03/0030/06/01).

\section{Contenidos:}

- Área I: Teoría e historia de la restauración.

- Área 2: Cultura e imágenes de historia de la arquitectura.

- Área 3: Metodologías y técnicas de estudios previos.

- Área 4: Técnicas de conservación.

- Área 5: Proyectos de conservación. análisis y estudios.

- Área 6: Legislación y economía.

Seminarios:

- La conservación de la arquitectura militar.

- Il seminario sobre bóvedas históricas, conocimiento, estudio y conservación.

- Il seminario sobre restauración, botánica y arquitectura en el proyecto de jardín.

- Pavimentos en espacios públicos.

- El color en la arquitectura.

- La restauración del edificios del movimiento moderno.

- Patrimonio histórico y barreras arquitectónicas.

Información:

Máster en Conservación del Patrimonio Arquitectónico

Escuela de Arquitectura Técnica de Valencia

Camino de Vera, s/n.

4607I Valencia

Amada Marín

Tel.: 96387705 ।

Fax: 96387705

Web: www.copa.upv.es

Correo-e: tipa@upvnet.upv.es 


\section{Máster en Arquitectura y Patrimonio Histórico (Universidad de Sevilla-Consejería de Cultura): balance y resultados en su tercera edición}

José Ramón Moreno Pérez Arquitecto y Profesor del Máster

Alcanza el Máster de Arquitectura y Patrimonio Histórico su tercera edición. Ha transcurrido suficiente tiempo como para estar en condiciones de hacer un cierto balance más o menos concluyente de los resultados de este producto, que en su arranque, fue una creación de la ingeniería docente.

Hay una primera conclusión, casi obvia para algunos, pero que es necesario volver a recordar por cuanto está en los fundamentos del mismo: esta experiencia docente e investigadora no habría podido llevarse a cabo sin el soporte de medios, conocimientos y profesionales del Instituto Andaluz de Patrimonio Histórico. Es esta una afirmación que no sólo hace justicia a quienes han sido nuestros promotores, valedores y amigos sino que nos hace consciente de hasta que punto ha sido esta una condición necesaria y suficiente para avanzar más allá de los límites convencionales de la docencia en arquitectura. Marca un límite, una frontera de no retorno, respecto a la cual la docencia de las escuelas de arquitecturas en este campo sigue estancada en el saber más añejo y caduco.

La segunda conclusión no es menos trascendental respecto al otro ámbito con el que se relaciona el Máster: el campo profesional. Y aquí también hemos ido mucho más allá de lo que fueron nuestras apuestas de partida. En primer lugar, el Máster está en condiciones de aportar un instrumental propio y específico de intervención en lo Patrimonial, que conjuga unas características que le permite superar antiguas contradicciones. Así, el llamado Proyecto Patrimonial ha sido capaz de recorrer todos los ámbitos de lo Patrimonial -desde la gestión a la conservación-, integrando las diferentes disciplinas, tradicionalmente presentes en este campo, con otras que cada vez se hacen más necesaria para la presencia del pasado en nuestra contemporaneidad. En segundo lugar, y aquí se encontraría una contradicción nada fácil de resolver, la formación del Máster está produciendo un nuevo perfil profesional, con una capacitación difícil de encajar en la actual compartimentación administrativa y funcional de competencias profesionales y áreas de trabajo. Con ello, el Máster se felicita de haber sido capaz de responder adecuadamente al reto planteado -ya en su arranque, por el IAPHde superación del enfoque disciplinar hacia, primero, uno interdisciplinar $y$, posteriormente, hacia lo transdiciplinar.

Pero estos logros no dejan de producir una sensación agridulce al revelarnos, por otra parte, los lími- tes de unos planteamientos y una estructuración que nos parecían suficiente hace unos años.

Esta es ya una docencia que no puede seguir denominándose como arquitectónica, sería injusto con todos los profesiones presentes en el Máster y con el compromiso que asumen, estamos definitivamente en un campo de nadie, si acaso en el del Patrimonio y ello con una necesaria definición de lo que entendemos por tal: un posible proyecto políticocultural que junto con el enfoque ecológico estaría en condiciones de vertebrar de forma diferente la sociedad actual.

Y desde esta tesis máxima es necesario volver a situar y definir los objetivos y la productividad de esta enseñanza respecto a sus marcos de implicación: el docente y el profesional. Si, por una parte, está claro que ya nos movemos en un diferente enfoque profesional y social; por otra, no terminamos de encontrar un ámbito adecuado para localizar docentemente esta enseñanza, de cara a alcanzar una productividad social y cognoscitiva idónea. Estas carencias no sólo afectan a una posible proyección futura del Máster, sino que incide en la marcha y programación de nuestra docencia e investigación, que se ve así necesariamente refrenada. Desde esta perspectiva, el Máster en Arquitectura y Patrimonio Histórico andaluz muestra unas características propia que lo hacen completamente diferente de los que figuran en la oferta de otras comunidades, con unos enfoque mucho más restringidos y convencionales; basta para comprobar lo dicho con repasar el listado que antecede a este artículo.

Por tanto, en esta coyuntura llena de logros y de inquietudes, esta tercera edición apunta hacia una necesaria redefinición de los objetivos, medios y procedimientos, que esperamos ser capaces de abordar definitivamente con la siempre necesaria ayuda de la institución, que más que una casi siempre ausente Universidad, se ha revelado como nuestra verdadera alma mater. 

El programa Máster de Restauración Arquitec-
tónica de la Universidad de Valladolid

Ignacio Represa

Dr. Arquitecto, Director del Máster

La Restauración Arquitectónica en España ha venido incorporando, desde mediados de los años ochenta, un creciente bagaje de conocimientos sobre la cultura material, derivados en parte de la intensa actividad de investigación en todas las materias disciplinares que pueden concurrir en el campo de la arquitectura, pero también como reflejo (algo tardío) de las experiencias francesas e italianas en las que siempre hemos basado, tradicionalmente, nuestro peculiar corpus doctrinal. Frente a la tradición artesanal en que se basó la actividad de la conservación de nuestros monumentos, surge hoy un campo complejo y especializado de conocimientos y experiencias que resultan inexcusables de dominar si queremos garantizar mínimamente la bondad de nuestras acciones de cara a una eficacia en las condiciones futuras de conservación de nuestro legado cultural. La historia de la restauración arquitectónica española está plagada de capítulos negros en los que supuestas medidas tenidas por correctoras, se erigieron en vehículos de aceleración de las velocidades naturales de destrucción, o en alteraciones arquitectónicas inadmisibles hoy para nuestro entorno cultural.

El año 1989, un grupo de profesores de la Escuela Técnica Superior de Arquitectura de la Universidad de Valladolid, consciente de la sentida carencia de foros de debate y estudio de los problemas y metodología del Proyecto de Restauración arquitectónica, nos propusimos, primero como cursos de Postgrado y desde 1995 como Máster, generar una titulación académica y curricular que hiciese frente al autodidactismo o los desplazamientos fuera de España, en que nos habíamos formado. Para tal empeño, y desde sus inicios, se tiene la colaboración permanente de la Dirección General de Patrimonio y Promoción Cultural de la Junta de Castilla y León, tanto en la cofinaciación de los cursos, como en el seguimiento de obras y proyectos de intervención en el patrimonio edificado.

El "Máster de Restauración Arquitectónica" es un titulo propio, de tercer ciclo, de la Universidad de Valladolid, con una carga lectiva de 5 I créditos, equivalente a 510 horas lectivas. El programa incluye la posibilidad de cursar tres especialidades: "Especialista en Teoría y Análisis del Patrimonio Histórico" con 20 créditos académicos, "Especialista en Técnicas y Procedimientos para la Restauración del Patrimonio Histórico" con 22 créditos, y "Especialista en Ciencias Auxiliares para la Restauración del Patrimonio Histórico" también con 22 créditos.

Los contenidos del Máster parten del entendimiento del proyecto arquitectónico como el instrumen- to idóneo e insoslayable del que debe surgir la restauración, y en él que deben incardinarse de manera crítica y científica todas las cuestiones que afectan a la conservación arquitectónica. Tal entendimiento no es solo una declaración de intenciones, sino que debe constituir el hilo conductor de las explicaciones teóricas y guión de las experiencias prácticas. La profusión de procedimientos de análisis y diagnóstico, o de intervención en el patrimonio, surgidos desde diferentes esferas del conocimiento y disciplinas académicas, en ocasiones con terminologías poco comunes, tienden a constituirse en cuestiones autónomas o compartimentos estancos que terminan por encajarse autónomamente en la obra de restauración, adquiriendo protagonismos que eluden la naturaleza arquitectónica, ante todo y sobre todo, que debe primar en el entendimiento de la restauración.

Sí compartimos estrategias y objetivos, poniendo en interrelación las distintas informaciones surgidas desde lo que debemos considerar como ciencias auxiliares para la restauración, en un proceso de proyecto, totalmente análogo al de proyectar la propia arquitectura, estaremos en condiciones de no provocar, por acción u omisión, lecturas fragmentadas u operaciones no controladas sobre la integridad del hecho arquitectónico y la complejidad de aspectos en que se manifiesta. Desde posibilidades tecnológicas y catálogos de productos, no surge la restauración, surgen operaciones fragmentarias con resultados no controlados en el mejor de los casos, y riesgos inasumibles para la integridad de la obra.

\section{CONTENIDOS DEL PROGRAMA}

Las asignaturas que integran el Plan de Estudios, se agrupan en torno a seminarios temáticos, con carga lectiva variable y horarios concentrados a lo largo del curso, cuyos objetivos y contenidos extraemos textualmente de nuestro programa:

\section{Teoría e historia de la restauración arquitectónica}

La finalidad de este seminario es la de contextualizar, desde una supuesta evolución de criterios y modelos, la experiencia histórica de la restauración arquitectónica.

Sus primeros temas introducen, profundizando en los debates barrocos e ilustrados, al proceso de valoración y conocimiento de la cultura clásica con que se inicia toda comprensión, no sólo de una ideal Antigüedad, sino del propio concepto de Occidente. Su herencia, en forma sistemática o "científica", fue recogida por el siglo XIX que inauguró tanto una apertura universal hacia la historia como el propio concepto moderno de restauración. En los temas que desarrollan estos aspectos se planteará ampliamente la condición ecléctica de la cultura decimonónica, que posibilitó el desarrollo de la interpretación 
constructiva de la arquitectura sobre la que se levantó la gran tradición racionalista personificada, entre otros, por Labrouste, Bötticher y Viollet-le Duc.

La cultura neorromántica de finales del pasado siglo marcó un giro radical en el concepto de restauración. En aquel momento se reconoce, gracias a la evolución de la arqueología, la complejidad estratigráfica de los vestigios del pasado, su carácter polimórfico, la "vida", en definitiva, del monumento. Desde la arqueología o la poética se asiste a un fenómeno paralelo de revitalización y fragmentación del objeto a restaurar cuyo carácter laberíntico, el racionalismo no acierta a comprender. Para ello se necesitaban nuevas actitudes intelectuales que complementasen la interpretación racional-constructiva. Gracias a las aportaciones de la arqueología desde los años treinta ha sido teorizada, a través de las diversas "Cartas", una actitud plural ante el monumento. Actitud que sitúa el debate contemporáneo, con inmensas apoyaturas en nuevos aspectos técnicos o histórico-documentales, en posición privilegiada para acceder a una clasificación, valoración y actualización del patrimonio.

\section{Análisis y valoración del patrimonio}

La conservación de las arquitecturas históricas constituye en nuestros días una de las actividades culturales que caracterizan, y definen, a nuestras sociedades. De la necesidad de su conservación, surgen las distintas operaciones (en ocasiones con terminologías confusas) que tienden a preservar y trasmitir tales objetos del pasado a las generaciones futuras. Los valores, que nuestra sociedad atribuye a tales arquitecturas, resultan de diversa índole y trascendencia de cara a explicar el conjunto de objetivos que nuestras acciones, la Restauración, deben contemplar.

Las primeras valoraciones establecidas, históricamente, surgieron del entendimiento del valor documental de las arquitecturas, a partir del propio nacimiento de la Historia, como disciplina académica, y el desarrollo metodológico de la arqueología, como ciencia histórica especializada. Esta valoración, con interpretaciones diversas, quedó ya incorporada desde finales del siglo XVIII al quehacer restaurador y continua aún vigente.

Determinadas arquitecturas, por su papel simbólico, cobraron desde su nacimiento consideraciones de valoración en sí mismas, lo que supuso, no sin transformaciones y adecuaciones a las distintas "exigencias" de los tiempos, actitudes culturales de conservación , con significados sociales de mayor trascendencia, que hoy identificamos genéricamente como señas de identidad de las colectividades y pueblos, hoy extendidas a todas las arquitecturas antiguas y muy valoradas a partir del resurgir de los nacionalismos.

Ambas valoraciones se pueden explicar a partir de la capacidad de las arquitecturas históricas de trasmitir- nos sensaciones, que ponen a cada espectador en una relación compleja con su historia, en la que se superponen las capacidades de evocación de las arquitecturas con los condicionantes culturales y sensibilidades, personales pero también colectivos, de cada espectador.

Más tardíamente surgieron conceptos, como la función social que englobando las valoraciones comentadas, incorporaron el valor del uso, y por tanto las cuestiones derivadas de su funcionalidad, como elementos apreciables en las arquitecturas del pasado, que impusieron nuevas maneras de entender la restauración.

Paralelamente, se vinieron desarrollando experiencias de interpretación de las arquitecturas del pasado, que han dado lugar a un corpus doctrinal, cada ve más depurado y compartido por las distintas sociedades, que constituye un bagaje importante cuyo conocimiento resulta inexcusable para el moderno restaurador.

El fruto de este bagaje puede hoy resumirse en tres grandes conjuntos de características, o aptitudes a tener por parte del restaurador, que definen la especialidad de esta faceta del quehacer arquitectónico:

- Sentido histórico, que permita tanto conocer que nuestra intervención se inscribe, a menudo como un breve episodio, en la vida del edificio, como que ésta va a ser revisada por actuaciones futuras, sometiéndose a una nueva revisión.

- Capacidad Técnica, en la que influirán los conocimientos específicos, en metodologías de diagnóstico y técnicas de restauración, que seamos capaces de adquirir e ir renovando en torno a las distintas experiencias del mundo cultural de la restauración.

- Capacidad artística, en las vertientes analítica y creativa, que permitan entender las potencialidades plásticas existentes (a menudo enriquecidas por los procesos históricos vividos por las edificaciones) y la necesidad de controlar el inneglable impacto estético que toda acción restauradora (incluso por omisión) supone para las arquitecturas.

El conjunto de lecciones en que se estructura el curso, se dirigen intencionadamente, en los sentidos enunciados, a abrir vías de conocimiento, a conocer los criterios actuales y a agudizar las capacidades de análisis, en definitiva, a entender aquellos aspectos metodológicos que resultan específicos del Proyecto de Restauración.

Procedimientos legales y administrativos para la Conservación y Restauración del Patrimonio Histórico

- Los poderes públicos y la conservación del patrimonio. Marco jurídico y administrativo.

El objetivo del seminario es ofrecer una mirada completa de la administración en la conservación 
del patrimonio, desde sus principios teóricos hasta su actividad concreta. Ello cobre una especial importancia ya que la conservación del patrimonio es una función pública en la cultura europea occidental. Todo este conjunto de materias se analizará desde la perspectiva del profesional encargado de la conservación del patrimonio, como herramienta que utiliza en su propio trabajo.

- Los instrumentos del planeamiento del patrimonio La referencia a los instrumentos de planeamiento general como uno de los principales elementos que conforman nuestro espacio tradicional es esencial, en la medida en que regulan los procesos transformadores del espacio y comportan la incorporación de otros instrumentos más específicos. A su vez, a partir de ahí, se planta exponer la diversidad de procedimientos que se despliegan desde la óptica de las distintas leyes que inciden en dicho proceso.

\section{Pretección e intervención en la ciudad histórica}

El seminario tiene como objetivo básico establecer los fundamentos de la intervención urbano-arquitectónica en la Ciudad Histórica. La intervención estará determinada en un extremo por la exigencia de protección y revalorización de los espacios o conjuntos que componen el patrimonio urbano. En el otro extremo la intervención está condicionada por la exigencia de introducir elementos de interpretación de la ciudad contemporánea, concebida como una realidad dinámica y vital, sujeta a la necesidad de transformación.

La interpretación acertada de la ciudad histórica es la primera condición que orienta la intervención, urbana $\mathrm{O}$ arquitectónica. Este curso procurará ofrecer los materiales adecuados para conocer, en primer lugar, la naturaleza del espacio urbano tradicional y, en segundo lugar, para aproximarse a cómo ha sido éste transformado en el tiempo. Desde la perspectiva histórica es posible describir cómo la ciudad ha sido interpretada y transformada a lo largo de sus diferentes momentos, cómo se ha configurado la cultura de protección de los Centros Históricos y cómo se ha desarrollado el contenido de los instrumentos urbanísticos dirigidos a la conservación y al control de las transformaciones del espacio tradicional.

Simultáneamente es preciso indagar en la cultura del proyecto, cultura que tiene en cuenta la formación histórica del espacio urbano y que dispone de una capacidad activa para reinterpretarlo desde la lógica que el propio tiempo define. Se abordan las claves materiales de la intervención: la geometría del lugar, la geometría de los trazados, las relaciones estructurales de lo edificado, los tipos que se articulan en tejidos urbanos. La interpretación tiene en origen una triple razón: topológica, morfológica y tipológica. Existe una cultura del proyecto que tiene en cuenta la formación histórica del espacio urbano, con una capacidad efectiva de reinterpretarlo y de considerar simultáneamente el contexto que el propio tiempo define, la lógica de los usos y de las funciones de un espacio urbano preconfigurado. Se forma así un complejo de relaciones en el que es difícil orientarse sin incluir la perspectiva histórica, es decir, sin la capacidad de reconocer el origen de los términos, de los materiales, instrumentos y conceptos que fundamentan y están presentes en los centros históricos: la geomorfología original del espacio, los trazados urbanos, la parcelación, los tipos edificatorios y los sistemas de agregación de éstos, las tradiciones en los usos, los significados simbólicos, el escenario de la identidad local...

Las necesidades sociales, económicas e institucionales, propias de cada tiempo, conviven en la ciudad histórica con la valoración cultural del patrimonio urbano y con la necesidad de conservarlo, un espacio que pertenece al paisaje de la identidad colectiva. Aunque la ciudad es siempre un espacio de cambio y de conflictos, donde lo que permanece dialoga con lo nuevo, compite y se yuxtapone, el territorio conserva su identidad a partir de los elementos que componen su patrimonio. El sistema de técnicas y de relaciones que fundamentan los instrumentos $y$ conceptos propios de la intervención en los Centros Históricos, su perspectiva conservadora, convive con una realidad multiforme en la que el proyecto urbano y arquitectónico contemporáneo tienen lugar polémicamente.

\section{Técnicas de análisis gráfico del patrimonio}

El necesario conocimiento previo del patrimonio arquitectónico que pretendemos proteger, se obtiene con una metodología específica que transciende de la habitualmente aprendida, en la medida en que se trata de edificios de gran valor cultural y, por tanto, de compleja lectura. Esto hace que surja un debate extenso, pluridisciplinar y rico en torno a los monumentos y su conocimiento.

Dado que la lectura del edificio se puede realizar desde posiciones distintas (arqueológica, funcional, compositiva, estructural etc.) se hace ineludible la participación de tantas disciplinas como sean necesarias para atender a todas las facetas que el monumento presenta y obtener, de todas ellas, la comprensión más completa posible.

Para poder llevar a buen fin las investigaciones sobre las diferentes interpretaciones del monumento se hace necesaria la utilización de un instrumento de pensamiento que sea más preciso que el lenguaje escrito, es decir, el dibujo.

Solo a través del dibujo podemos poner en relación los datos obtenidos para descripción de cada estadio, también podemos comprobar la correspondencia de los datos descriptivos con los registros arque- 
ológicos y acercarnos al proceso de pensamiento del artista que intervenía en el edificio en cada momento y que, seguramente, utilizó el dibujo para la realización de sus propuestas.

Dada la imposibilidad de reconstruir físicamente la situación de cada fase histórica del edificio, tanto en su aspecto formal como con respecto a su entorno, nos serviremos del dibujo como mecanismo que nos permite realizar un simulacro formal del mismo $y$, de esta manera, comprobar aquellos datos cuya mera descripción no basta para su total comprensión, acercándonos a la realidad física del problema arquitectónico-histórico que queremos resolver.

Esta utilización del dibujo como instrumento de pensamiento arquitectónico, tanto de proyectos futuros como pasados, resulta familiar en la cultura arquitectónica general y comienza a ser imprescindible en la elaboración de los estudios históricos de cualquier monumento, más aún si se pretende restaurar.

Para poder realizar la investigación con rigor debemos partir del registro gráfico de la realidad formal del edificio, es decir, del levantamiento gráfico. En la precisión y exactitud de este punto de partida fundamental, basaremos gran parte de nuestras conclusiones, lo cual nos obliga a prescindir de levantamientos convencionales, con escasos datos comprobados, que tienden a idealizar la forma del monumento y acudir a lo que denominamos levantamiento científico donde se refleja la forma real y objetiva del edificio.

La utilización de un levantamiento de la forma aparente del monumento (levantamiento habitual) no nos sirve, ya que el registro de las imperfecciones, cambios de técnica constructiva, contradicciones en la geometría, etc., son, en la mayoría de los casos, los datos que nos sirven para entender las transformaciones del edificio.

Así el levantamiento gráfico se nos presenta como el soporte fundamental para el conocimiento del monumento, no sólo por su carácter descriptivo sino en cuanto documento de partida sobre el cual incorporar y analizar la información obtenida de los análisis complementarios realizados: comportamiento estructural, sucesivas intervenciones, etc.

La lectura de la forma arquitectónica mediante el levantamiento permite descubrir cambios y transformaciones del edificio que no son perceptibles a simple vista y que pueden aclarar, en gran medida, las dudas derivadas del conocimiento del monumento realizado por otras vías paralelas.

La lectura arquitectónica de un monumento dará pie a multitud de nuevas vías de investigación que utilizarán las conclusiones derivadas del análisis realizado y las opondrán a las efectuadas desde otras posiciones para seguir avanzando en el conocimiento del mismo.

\section{Historia de los procesos constructivos}

Para poder intervenir en la restauración de un edificio debe conocerse a fondo la constitución del edificio mismo que es objeto de tal restauración arquitectónica. Esta asignatura centra sus esfuerzos en conocer qué materiales y con qué leyes de organización y estabilidad han sido dispuestos a lo largo de la historia para estar en disposición de dar realidad física a la forma arquitectónica construida.

La Historia de los procesos constructivos ha de entenderse aquí, no como mera descripción de los usos y costumbres de construir en cada época, sino como expresión viva de un desarrollo y una evolución continua, que es preciso conocer para entender los aspectos constructivos y de proyecto de los edificios del pasado y, más aún, para intervenir en ellos.

Así, podrán evitarse soluciones de intervención restauradora excesivamente duras, desproporcionadamente tecnológicas o, simplemente antieconómicas, si se conocen a fondo los procesos constructivos y su evolución y alternativas planteadas en su propio contexto temporal. Sólo entonces estaremos en disposición de rescatar aquellos principios constructivos o formales válidos y utilizables en las actuaciones del momento presente.

Comprender mejor las pautas de restauración de un edificio y tomar las decisiones de actuación con coherencia obliga a que sea preciso conocer el modo de construcción que tiene vigencia en cada momento de su historia y las razones del mismo.

Además, el conocimiento específico de los procesos constructivos que se detectan en las distintas partes y modificaciones de diversas épocas históricas ha de permitir individualizar el edificio sobre el que se ensaya la labor restauradora y, por tanto, adoptar soluciones exclusivas y diferentes para cada uno de los problemas planteados, sin caer en la aplicación indiscriminada de las recetas o lugares comunes al uso.

Por otra parte, la restauración en Arquitectura alcanza hoy día a toda la tradición del Movimiento Moderno y, por tanto, su propia vicisitud, en razón de su influencia y de lo reciente de su período de desarrollo, debe ser considerada dentro del Curso.

En ese mismo "tempo histórico", se produce el cenit de la evolución respecto a la aparición de nuevos materiales y a la mejora de los tradicionales, en tanto que comienza una auténtica revolución en lo que se refiere a la organización de las obras y a la producción de los rendimientos y de los medios auxiliares de la construcción.

El seminario presenta su programa mediante la articulación de tres líneas de investigación, bien diferenciadas, pero no por ello menos independientes, que son: 
- Relación entre Arquitectura y Construcción material y formal de la misma. La Construcción, desde la influencia teórica y empírica, en la disciplina de la Arquitectura.

- Elementos históricos y principios formales de Construcción. En tanto en cuanto determinada construcción se asocia o no a determinado Elemento de Arquitectura, histórico o actual, y lo modifica al introducirse otro criterio constructivo o material distinto.

- Elementos, técnicas y materiales de construcción que componen el desarrollo de los procesos constructivos. Disposición de materiales. Evolución de los mismos, de su utilización física, adecuación, significación, herramientas y oficios.

En definitiva, desde un nivel de reflexión en el contexto y papel propio de la Construcción en la Arquitectura, se inicia un recorrido que arranca en los primeros y más simples procesos constructivos para llegar, a través de sucesivas experiencias en el tiempo, a un corpus de saberes que ofrecen "elementos más o menos acabados" y cuya utilización meramente operativa puede hacer perder los criterios de adecuación y significación a que propende la Construcción de la Arquitectura.

\section{Técnica de análisis de materiales y diagnóstico}

Todo material constructivo, proveniente de la naturaleza o fabricado industrialmente, por su mera ubicación en la atmósfera terrestre sufre con mayor o menor intensidad, alteraciones físico-químicas de sus características compositivas. El agua y su capacidad de disolución de sales componentes, los fenómenos de heladicidad, la oxidación, la pudrición de materiales orgánicos, los fenómenos de contaminación atmosférica, los biodeterioros, etc., son procesos destructivos comunes que podemos reconocer en cualquier arquitectura incluso en las de reciente edificación.

Conocer como operan sobre la materia los distintos agentes, la interacción sobre un mismo material de distintos fenómenos destructivos (o transformadores), la velocidad de evolución de tales procesos y el establecimiento de hipótesis y modelización de comportamientos en tiempos futuros, son datos ineludibles de conocer de cara a garantizar una intervención que pretendemos restauradora.

Por otra parte la adopción de medidas correctoras de la capacidad de incidencia de tales fenómenos debemos entenderla como el resultado de una experimentación conocida y garantizada, ensayada previamente que evite los siempre presente riesgos de provocar a medio plazo de tiempo situaciones de alteración más graves que las encontradas antes de nuestra intervención.

\section{Introdicción a las ciencias auxiliares}

La intención de este seminario es desarrollar los conocimientos necesarios para enfrentar la frecuente aparición de problemas no específicamente arquitectónicos en la restauración de edificios históricos. Este desarrollo se produce no sólo en un nivel necesario para garantizar el enfrentamiento con las precisas y diferenciadas cuestiones que caracterizan la solución de los problemas mencionados.

La presencia del arqueólogo y de sus métodos de conocimiento en los procesos de restauración resulta imprescindible tanto como elemento auxiliar en la comprensión de los monumentos como en la aportación a la propia teoría de la intervención en el patrimonio. En este sentido la disciplina arqueológica ha desarrollado un método científico de conocimiento de la cultura material que se puede aplicar con precisión a los edificios colaborando con rigor en la comprensión de nuestro legado arquitectónico.

Recíprocamente la aportación del arquitecto a los estudios arqueológicos en los que aparecen restos arquitectónicos puede considerarse de vital importancia ya que añadirá a la discusión interpretativa, los aspectos derivados de la disciplina que generó el objeto material analizado, atendiendo a relaciones espaciales, compositivas, de uso, constructivas o degradadoras y estableciendo los criterios junto con los arqueólogos para su conservación o puesta en valor.

El valor de un monumento arquitectónico considerado Bien de Interés Cultural no reside solamente en su calidad artística sino en la consideración del mismo como documento histórico, presentándose como una unidad espacial conseguida por una serie de relaciones materiales dadas a lo largo del tiempo histórico.

Es evidente que existe una clara ampliación del conocimiento histórico derivada de la utilización de fuentes diversas a las tradicionales, así como por el interés por otros protagonistas de la historia diferentes de los que habitualmente forman parte de los acontecimientos históricos.

Las investigaciones del historiador actual se alejan de los hechos cualitativamente relevantes que forman parte de la historia tradicional para preocuparse de los hechos cuantitativamente importantes que nos puedan dar una visión diferente de la sociedad y que nos permita entender los primeros en su contexto. Se hace necesario el conocimiento de las estructuras sociales, de los sistemas de producción, de los espacios donde se relacionan, etc., prescindiendo de valores que hagan figurar unos por encima de otros.

Este modelo de hacer historia pasa necesariamente por analizar la herencia material que nos rodea, usándola como fuente $y$, que duda cabe, que la arquitectura constituye parte esencial de esa cultura material. 
Así la arquitectura ha comenzado finalmente a entenderse como el directo resultado del trabajo material del hombre, identificándose cuantitativamente con la propia historia de las clases populares, de las clases subalternas, hecha de ladrillos, piedra, morteros, Historia que, al contrario, hasta ahora, ha sido escrita por y para las clases dirigentes, las élites aristocráticas, o simplemente no estaba escrita.

La visión del monumento ya no pasa por entenderlo como la obra de un artista concreto o el encargo de un personaje histórico, o el lugar de un acontecimiento relevante, la fabrica del ladrillo en sí misma, considerada como consistencia física, además constituye la acumulación de otros hechos históricos de la vida cotidiana.

De hecho, desde esta visión de la historia no se puede pasar por alto la circunstancia que entre todas las fuentes utilizadas, la fuente por excelencia, el referente principal, fundamental e imprescindible es la misma fábrica como estructura significante.

Esta ampliación de la forma de entender el legado arquitectónico aumenta considerablemente el parque construido que la propia sociedad entiende como parte de su cultura $y$, consecuentemente, condiciona sustancialmente la actitud ante su conservación.

También se abordarán las exigencias específicas y los criterios que informan la instalación de colecciones y la transformación en museos de edificios históricos. Se trata de una operación bien repetida en la cultura moderna y que exige un concreto y especializado conocimiento de sus características.

Finalmente, se trabajará en las técnicas de restauración de los diversos objetos y técnicas ornamentales que, pertenecientes a disciplinas diferentes de la arquitectónica constituyen un lugar de conocimiento necesario para quienes pretenden acercarse a la restauración y es un territorio de trabajo concreto para toda una serie de especialistas. A ambos pretende atender este seminario. La visión del monumento se realiza ahora en su totalidad, como realidad física sometida a continuas degeneraciones, derivadas del uso, de la meteorización, de la acumulación de transformaciones vivas.

\section{Procedimientos técnicos para la restauración}

El objetivo principal del Seminario es el acercamiento al conocimiento del conjunto de las técnicas de intervención disponibles en este momento, y a una visión global de las mismas en el contexto de la problemática de cada edificio, de la metodología aplicada, y de la relación entre proyecto y obra.

Se pretende ofrecer una visión crítica de los procedimientos utilizados a lo largo de la historia en los edificios, y de aquellas técnicas y prácticas que han sido habituales en un pasado mucho más reciente.
El estudio y análisis de las técnicas antiguas, su seguimiento en manuales y tratados, y el intento de recuperación de oficios y tradiciones que débilmente perduran, será otro de los objetivos a lo largo del curso.

En el entendimiento de proyecto y obra como dos partes indesligables de un mismo proceso, se reflexionará sobre la incidencia de los tratamientos en las edificaciones históricas, y sobre la importancia y necesidad del control permanente en las mismas.

Dentro del carácter de visión global que tiene el Seminario, se ofrecerán aspectos específicos y aplicaciones prácticas no sólo de los procedimientos considerados como sofisticados, sino también de aquellos tratamientos tradicionales cuya aplicación es hoy perfectamente posible.

Contamos hoy con muchas ventajas frente a los antiguos procedimientos, desde los modernos análisis físico-químicos a los controles de dosificaciones en mezclas y componentes, comprobándose como serán aquellas operaciones referidas a la estricta manualidad, al oficio, las de mayor dificultad en recuperarse.

El Seminario incide igualmente sobre sistemas constructivos que la experiencia indica como más significativos de entre los que forman parte de lo que podríamos llamar tradicionales en las edificaciones históricas.

De entre todos los problemas que plantea la Restauración uno de los más delicados es el de la intervención en las fachadas y elementos ornamentales de piedra en los Monumentos, pues en ellos se concentra una gran parte del significado histórico-artístico y las actuaciones son siempre, en cierta medida, irreversibles.

\section{Proyectos de restauración}

Dentro de las actividades del Curso se deberá realizar con carácter obligatorio un Proyecto de Restauración sobre un edificio y su entorno, trabajando sobre los diversos aspectos que son inherentes a la conservación del legado arquitectónico.

- Definición del carácter y principales ideas que deben soportar de la actuación

- Valoración histórica y arquitectónica del edificio.

- Consideración de los aspectos funcionales y distributivos del edificio, mantenga o modifique éste su uso anterior.

- Resolución de los problemas físicos del edificio.

- Consideración y valoración del entorno

Se trata de reunir en el trabajo a realizar dentro de este seminario, la comprobación práctica de las 
aportaciones teóricas suministradas al alumno por el resto de seminarios, además de procurar la comprobación, sobre un tema real, de las dificultades y singularidades que se presentan en proyectos de esta naturaleza frente a la generalidad de la proyectación arquitectónica.

Desarrollaremos, por tanto, un proyecto en todas sus facetas de índole específicamente arquitectónica, iniciándose el primer año en una toma de datos que incluya la restitución planimétrica $A$ lo largo del curso se estructurará un taller de proyectos en el que la actividad fundamental será el seguimiento de los trabajos realizados por los alumnos, con aportaciones de los profesores en clases de apoyo a los problemas específicos que en cada momento se desarrollen. Se producirán también intervenciones de profesores de otros seminarios, cuando se precise un mayor nivel de especificidad en las aportaciones teóricas.

Cada alumno trabajará bajo la supervisión directa de un Tutor, nombrado por la Dirección del Máster. La realización y positiva clasificación de este seminario serán decisivas en la valoración global del curso entero.

El Programa Máster de Restauración Arquitectónica publicará bianualmente una selección de todos los proyectos aprobados.

\section{Ejecución de obras de restauración}

Este seminario pretende formar a los asistentes al curso en la realidad física del trabajo de restauración de edificios históricos, proporcionándoles visitas directas a obras en curso o finalizadas que presenten especial interés a causa de los problemas abordados, los procedimientos utilizados, las soluciones técnicas empleadas, las opciones proyectuales escogidas, la singularidad del edificio o de su específica idoneidad como ilustradoras de cuestiones esenciales de la teoría impartida en el resto de los seminarios.

Los alumnos pueden apreciar de modo directo la concreta aplicación práctica de sus conocimientos e introducir en la escala adecuada la información que previamente se les ha suministrado. Supone además un momento de especial relación con los profesores encargados de las visitas, por cuanto pueden desarrollarse aquí explicaciones directamente en obra de problemas de frecuente frialdad teórica pero compleja aplicación práctica.
Sus actividades suponen un alto en la actividad semanal del curso, dedicándose días completos a las visitas programadas y compartiendo con profesores de otros seminarios la experiencia de este acercamiento a los problemas de la ejecución real de las obras.

A lo largo del próximo curso están programadas ocho sesiones del seminario, cuya realización está coordinada con el Servicio de Restauración de la Consejería de Educación y Cultura de la Junta de Castilla y León, a fin de proporcionar la presencia en obra de los directores facultativos, los representantes de la empresa y cuantas personas forman parte de la realidad diaria de los trabajos, proporcionándose explicaciones "in situ" sobre la naturaleza de los trabajos desarrollados y sus principales características e incidencias.

\section{El debate contemporáneo en la restauración arquitectónica}

Si la generalidad de los seminarios del curso se centran en la exposición del estado presente de los conocimientos de una serie de disciplinas auxiliares de la restauración arquitectónica, la propuesta de "El debate contemporáneo..." consiste en el contraste de diferentes puntos de vista y en la exhibición de reflexiones o trabajos vinculados a la restauración, por parte de reconocidos expertos nacionales e internacionales en la materia.

Las sesiones se desarrollan en la semana final del curso y suponen el momento en que las actividades del curso se abren a la opinión pública en general -con la asistencia de oyentes y estudiosos no implicados permanentemente en las actividades del curso- para que ésta pueda conocer y participar del esfuerzo de las entidades convocantes por aproximar a la sensibilidad de la sociedad un capítulo tan esencial de nuestra cultura como es la conservación y restauración material de su pasado.

Los invitados a participar en "El debate..." son escogidos de entre las variadas áreas de conocimiento que están relacionadas con el objeto central del curso, de modo que se encuentren representados todos los aspectos que inciden en la realidad habitual de la actividad del restaurador. 